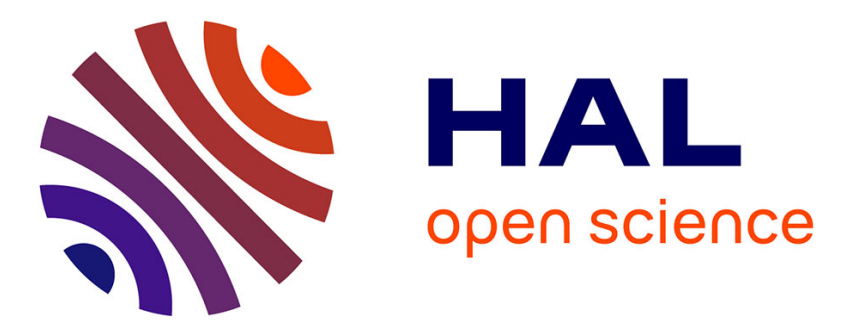

\title{
Experimental study of a high speed punching process
}

Arnaud Larue, Nicolas Ranc, Y.F Qu, Marius Millot, Philippe Lorong, F. Lapujoulade

\section{To cite this version:}

Arnaud Larue, Nicolas Ranc, Y.F Qu, Marius Millot, Philippe Lorong, et al.. Experimental study of a high speed punching process. International Conference on High Speed Industrial Manufacturing Processes, 2007, Cenlis, France. 10.1007/s12289-008-0104-2 . hal-00283228

\section{HAL Id: hal-00283228 \\ https://hal.science/hal-00283228}

Submitted on 13 Aug 2020

HAL is a multi-disciplinary open access archive for the deposit and dissemination of scientific research documents, whether they are published or not. The documents may come from teaching and research institutions in France or abroad, or from public or private research centers.
L'archive ouverte pluridisciplinaire $\mathbf{H A L}$, est destinée au dépôt et à la diffusion de documents scientifiques de niveau recherche, publiés ou non, émanant des établissements d'enseignement et de recherche français ou étrangers, des laboratoires publics ou privés. 


\title{
Experimental study of a high speed punching process
}

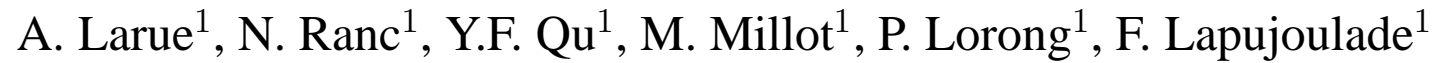

${ }^{1}$ L.M.S.P., U.M.R. C.N.R.S. ${ }^{\circ}$ 8106, Arts et Métiers ParisTech

151, boulevard de l'Hôpital, 75013 Paris

URL: www.paris.ensam.fr/lmsp

e-mail: philippe.lorong@ paris.ensam.fr

ABSTRACT: Punching process is increasingly used in industry. The punching speeds increase induces the generation of new mechanisms which are characterized by high strain rates like strain rate hardening of materials. The increase of the punching speeds also involves the formation of adiabatic shear bands (ASB). These effects result in improving the cutting quality. The critical releasing speed of the observed phenomena depends on the workpiece material properties and on the process parameters. To understand and identify the activated mechanisms, a high speed punching device has been developed. The proposed device enables the user to regulate a gap between punch and die of about $0.1 \mathrm{~mm}$ with a precision of $0.02 \mathrm{~mm}$. In this paper we will present various aspects related to the design of the punching device and an analysis of measurements obtained for a micro alloy steel S600M.

KEYWORDS: punching device, adiabatic shear bands, high speed punching

\section{INTRODUCTION}

Punching is a very common technique in industry. The thicknesses of the punched plates can vary from less than one millimetre up to more than ten millimetres. Classically, the punching speed reaches up to 4 $\mathrm{m} / \mathrm{s}$. Function of the awaited cutting quality, the gap between die and punch is then regulated at a certain value varying from $4 \%$ up to $10 \%$ of the workpiece thickness.

In order to improve the cutting surface quality, the fatigue strength of the workpiece, the residual stresses and the production rates, it seems interesting to increase the punching speeds. However, such an increase can involve new strain and fracture mechanisms which are characteristics of the dynamic loading.

Increasing the punching speed generates an increase in the strain rate and therefore a dynamic hardening of the material. On the other hand, the plastic energy is dissipated into heat during the cutting process and consequently, there is a significant increase of temperature because of the small loading duration. Opposite to dynamic hardening, this increase of temperature generates a thermal softening of the material and thus a yield stress reduction. Moreover if the punching speed is high enough, it is then possible to observe the formation and propagation of an adiabatic shear band $[8,1]$.

Considering the difficulty of designing a dynamic punching device and considering the difficulty of getting accurate measurements with very short response times, only a few studies have been carried out to understand and model the mechanisms of a high speed punching process. However, it is possible to mention the experimental work of Roessig and Mason [9, 7, 5] who studied the dynamic punching with a speed range until $30 \mathrm{~m} / \mathrm{s}$ and using a gap between die and punch higher than or equal to $1,6 \mathrm{~mm}$. Numerical studies were also carried out trying to understand the mechanisms of adiabatic shear band propagation $[10,6]$.

In the current study, a punching device has been designed allowing high speed punching. The paper is structured into two parts: The first part presents the experimental punching device as well as the different measurement systems and the second part presents and discusses the obtained results for the cutting of a micro alloy steel S600M.

\section{EXPERIMENTAL DEVICE}

\subsection{Solicitation device}

The experimental punching device was designed to allow a punch to be launched with a feed varying from 5 
to $25 \mathrm{~m} / \mathrm{s}$. The punch mass can vary from 0.5 to $2 \mathrm{~kg}$. A linear architecture including a launching system per compressed-air gun was retained. Figure 1 shows the general organization of the punching test bench. This device is based on the following principle. A linearly guided punch, strikes a sheet band located on a die constituted by two parallel sharp edges. The tested band of material is about $17 \mathrm{~mm}$ long and its thickness can vary from 1 to $8 \mathrm{~mm}$.
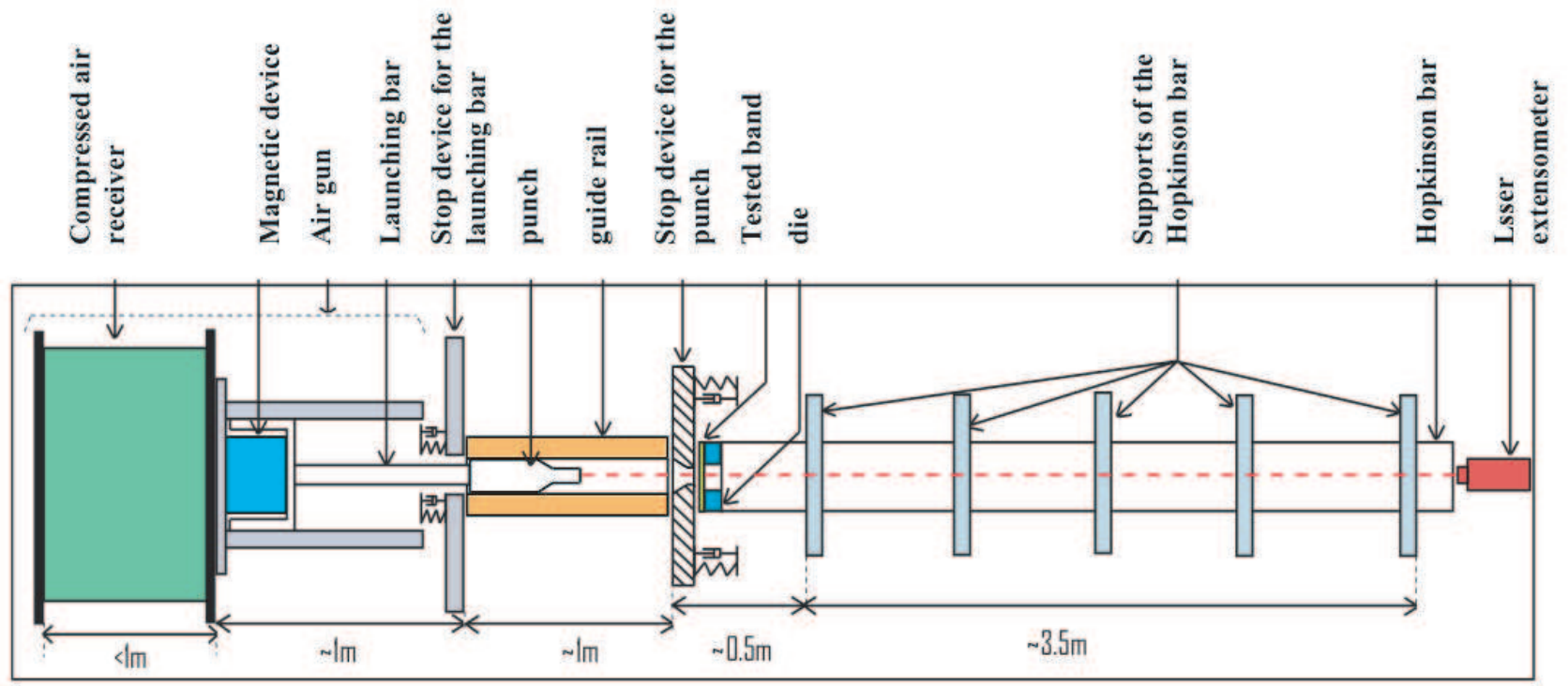

Figure 1: Schematic drawing of the punch loading device

From the left to the right, the experimental bench contains the following items:

- an air gun; the shooting duration being very short, we use an electro-magnetic device to retain the launching bar whereas the air receiver is under pressure; from the safety point of view, we use a magnetic device whose force is cancelled as soon as this device is fed,

- a stop device for the launching bar, making it possible to stop he punch stem before the punch strikes the workpiece (only the kinetic energy of the punch takes part in the cutting mechanisms),

- a linear guide systema

- a stop device allowing the final stop of the punch after cutting,

- a die for the cutting,

- an Hopkinson bar device,

- a laser extensometer allowing the punch feed measurement.

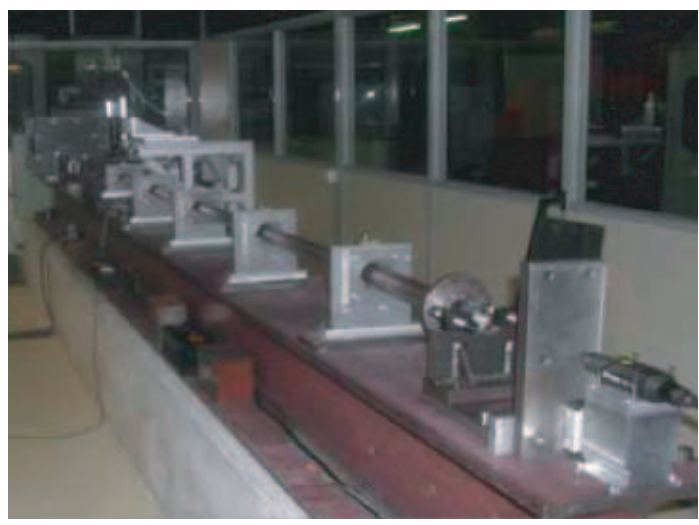

Figure 2: A view of the experimental punching device

The repeatability of the ejection speed of the punch has been proved and is considered equal to $0.1 \mathrm{~m} / \mathrm{s}$. This device contains a hydraulic control system allowing the user to adapt the pressure in the air receiver according to the awaited launching speed.

The linear guide system allows insuring a minimal gap of $0.02 \mathrm{~mm}$ between the cutting punch flanks and each cutting face. The die, linked to the Hopkinson bar, allows: the evacuation of the sheared part, the observation of the cutting zone and an accurate precision concerning the cutting faces location. Figure 3 presents the retained die geometry. 


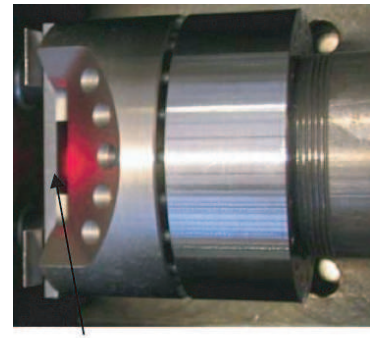

Tested band of material

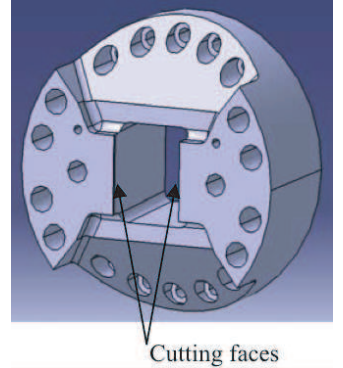

Figure 3: Schematic drawing of the die

\subsection{Punch velocity and cutting forces measurement}

A laser extensometer is used to measure the velocity of the punch end. This measure is carried out using a sampling rate of $1 \mathrm{MHz}$.

To measure the forces evolution during the cutting process and especially during the formation of the shear band, i.e. during a period of time less than $50 \mu \mathrm{s}$, an Hopkinson tube is used. A die and the workpiece to be tested are located on this tube (figure 3). Two deformation gages are sticked on the tube and located at a distance of $L=0.49 \mathrm{~m}$ from the die. An amplifier whose cut-off frequency is $500 \mathrm{kHz}$ and a data acquisition system allow recording the temporal evolution of the strain in the tube.

The axial load on the tube can be determined from the elastic theory of waves propagation:

$$
F_{\text {tube } \rightarrow \text { die }}=\text { E.S.E }\left(t-\frac{c}{L}\right)
$$

where $E, S$ and $c$ are respectively the Young modulus $(E=210 \mathrm{GPa})$, the section $\left(S=6.38 \cdot 10^{-4} \mathrm{~m}^{2}\right)$ and the longitudinal waves celerity $(c=5200 \mathrm{~m} / \mathrm{s})$ of the tube. $\varepsilon(t)$ is the strain measured using the gages.

We can also express the tested material speed at the end of the tube :

$$
v_{\text {tube }}=c . \varepsilon\left(t-\frac{c}{L}\right)
$$

Considering the die as rigid, the cutting force $F_{\text {cutting }}$ can be evaluated from its mechanical equilibrium:

$$
2 F_{\text {cutting }}=m_{m} \cdot \frac{\mathrm{d} v_{m}}{\mathrm{~d} t}+F_{\text {tube } \leftarrow \text { die }}
$$

where $m_{m}=0.846 \mathrm{~kg}$ is the mass of the die and $v_{m}$ the speed of the die.

\section{RESULTS AND DISCUSSION}

A trial run was carried out on micro alloy steel samples S600M with fixed mass for the punch $(1.5 \mathrm{~kg})$. The sample has a parallelepiped geometry: width $17 \mathrm{~mm}$, length $5 \mathrm{~mm}$ and thickness $2 \mathrm{~mm}$.

Figure 4 presents the feed evolution of the punch according to the time. For this test, the gap between die and punch is equal to $0.18 \mathrm{~mm}$ and the punch speed is equal to $7.1 \mathrm{~m} / \mathrm{s}$ before the beginning of the cutting. At the end of the cut, the punch speed oscillates around an average value estimated at $2.6 \mathrm{~m} / \mathrm{s}$.

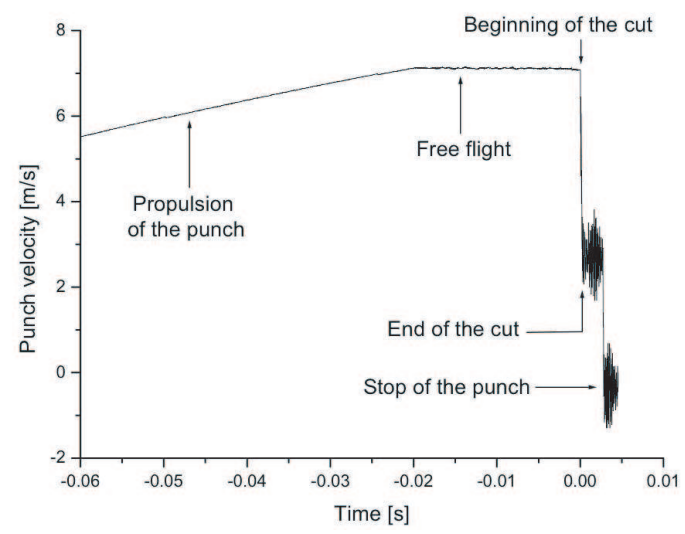

Figure 4: Speed evolution of the punch during a cutting test

Figure 5 focuses on the cutting zone presented figure 4. The velocity signal exhibits oscillations and seems strongly marked by a dominating harmonic around $20 \mathrm{kHz}$ (the first eigen frequency of the punch).

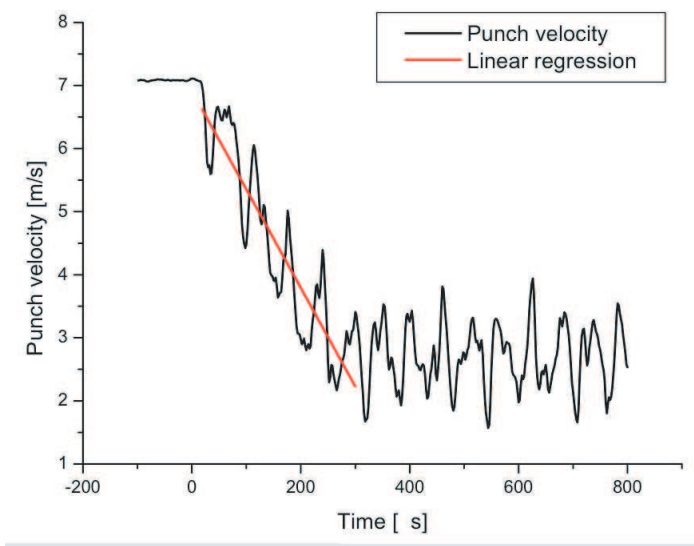

Figure 5: Enlargement of the punch velocity evolution versus time

The collected experimental data allow the determination of the applied force applied on the punch during the cutting sequence. If the punch is considered as rigid, the fundamental dynamic equation gives: 


$$
F_{\text {cutting }}=\frac{1}{2} m_{p} \frac{\mathrm{d} v_{p}}{\mathrm{~d} t}
$$

where $m_{p}$ and $v_{p}$ are respectively the mass of the punch and its velocity.

The average acceleration of the punch is calculated by linear regression of the velocity curve in the cutting zone (straight line in red on figure 5). For the considered test the cutting force estimation is $11.7 \mathrm{kN}$.

Figure 6 shows the cutting force evolution versus time coming from the measurement of the gauges. The curves in black and red respectively correspond to the cutting forces obtained by neglecting the die inertia and correspond to the cutting forces obtained by taking this inertia into account. A very fast increase of the cutting force can be observed (the increase time is estimated around $50 \mu \mathrm{s}$ ) and this increase phase is followed by a very small decrease during the cutting phase. The maximum cutting force is equal to $10.3 k N$ and the average cutting force can be estimated approximately equal to $8.9 k N$ that is slightly lower than the effort previously estimated from the punch. The total duration of the sample solicitation is approximately equal to $260 \mu \mathrm{s}$.

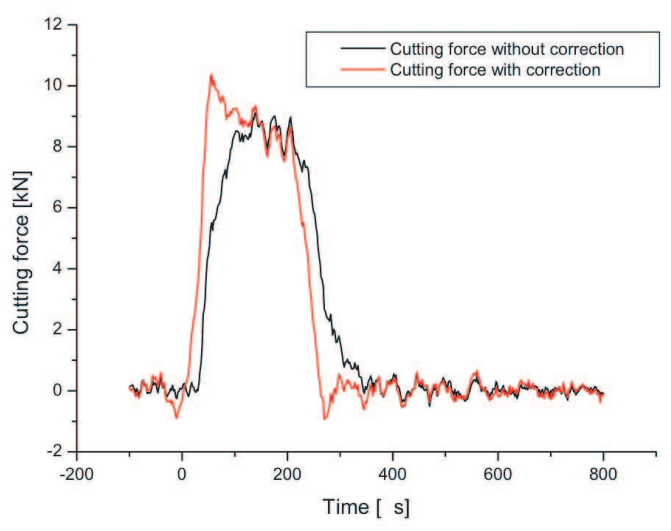

Figure 6: Measurement of the cutting force with the Hopkinson bar device

A study dealing with the effect of the dispersion of the compression waves in the tube showed that this effect contributes only for $5 \%$ in our experiments $[3,4,2]$.

\section{CONCLUSIONS}

We developed a dynamic punching device enabling to reach cutting speeds going from 5 to $25 \mathrm{~m} / \mathrm{s}$ and a gap between die and punch which was fixed at $0.18 \mathrm{~mm}$ with a precision of $0.02 \mathrm{~mm}$. The punching device now could be used to analyze the mechanisms governing the adiabatic phenomenon in cutting. Its configuration also allows performing tests in adequacy with the industrial constraints, generally expressed by the manufacturers of blanking machine. Indeed, the designed device allows varying the gap of cutting, the impact speeds, the design of the cutting section as well as the mass of the punch. It is in particular planned soon to define cutting tests on closed profiles. Such punching tests are still very difficult to handle industrially with cutting speeds allowing the activation of adiabatic shearing mechanisms.

\section{ACKNOWLEDGEMENT}

This work has been done under the technical and financial support of CETIM Senlis (Centre Technique des Industries Mécanique).

\section{REFERENCES}

[1] Y. Bai and B. Dodd. Adiabatic shear localization? Occurrence, Theories and Applications. Pergamon Press, Oxford, 1992.

[2] P. S. Follansbee and C. Franz. Wave propagation in the split hopkinson pressure bar. J. E. Mater. Tech., 105:6166, 1983.

[3] G. Gary and H. Zhao. A three dimensional analytical solution of the longitudinal wave propagation in an infinite linear viscoelastic cylindrical bar. Application to experimental techniques. Journal of the Mechanics and Physics of Solids, 43(8):1335-1348, 1995.

[4] D. A. Gorham. A numerical method for the correction of dispersion in pressure bar signals. J. Phys. E: Sci. Instrum., 16:471-419, 1983.

[5] P. Guegan and A. Poitou. An experimental investigation of orthogonal cutting advanced measurement techniques and machinability aspects. Int. J. of Forming Processes, 9(4):473-489, 2006.

[6] S.N. Medyanik, W.K. Liu, and S. Li. On criteria for dynamic adiabatic shear band propagation. Journal of the Mechanics and Physics of Solids, 55(7):1439-1461, 2007.

[7] K. M. Roessig and J. J. Mason. Dynamic stress intensity factors in a two dimensional punch test. Engineering Fracture Mechanics, 60(4):421-435, 1998.

[8] K. M. Roessig and J. J. Mason. Adiabatic shear localization in the dynamic punch test, part i: experimental investigation. Int. J. Plasticity, 15(3):241-262, 1999.

[9] K. M. Roessig and J. J. Mason. Adiabatic shear localization in the dynamic punch test, part ii: numerical simulations. Int. J. Plasticity, 15(3):263-283, 1999.

[10] X. Teng, T. Wierzbicki, and H. Couque. On the transition from adiabatic shear banding to fracture. Mechanics of Materials, 39(2):107-125, 2007. 